\title{
Polyethyleneimine/activated carbon paper-based material for low-concentration hexavalent chromium removal
}

\section{Tianliang Gao}

Qilu University of Technology

Chuanshan Zhao (D ppzcs78@163.com)

Qilu University of Technology https://orcid.org/0000-0002-9716-6001

\section{Sha Wang}

Nanjing Forestry University

\section{Xia Li}

Qilu University of Technology

\section{Research Article}

Keywords: Activated carbon paper-based material, Polyethyleneimine, Adsorption, low-concentration hexavalent chromium

Posted Date: January 25th, 2022

DOI: https://doi.org/10.21203/rs.3.rs-1224134/v1

License: (c) (i) This work is licensed under a Creative Commons Attribution 4.0 International License. Read Full License 
1 Polyethyleneimine/activated carbon paper-based material for low-concentration

2 hexavalent chromium removal

3 Tianliang Gao ${ }^{\mathrm{a}}$, Chuanshan Zhao ${ }^{\mathrm{a}}$, Sha Wang ${ }^{\mathrm{b}}, \mathrm{Xia} \mathrm{Li}^{\mathrm{a}}$

a.State Key Laboratory of Biobased Material and Green Papermaking, Qilu University of Technology,

$5 \quad$ Shandong Academy of Sciences, Jinan, 250353, China

b.Jiangsu Co-Innovation Center of Efficient Processing and Utilization of Forest Resources, Nanjing

7 Forestry University, Nanjing, 210037, China

*Corresponding author: Chuanshan Zhao

Tel: +8613606400139

Author information:

Abstract In this study, softwood pulp, activated carbon powder, and polyester fiber were prepared into activated carbon paper-based materials $(\mathrm{ACPBM})$ by papermaking. Then the polyethyleneimine (PEI) is loaded on the activated carbon paper-based material by dipping to prepare a high-performance, green PEI/activated carbon composite paper-based adsorbent material (PPCA) to remove low concentrations of Cr(VI) in water. The surface characteristics of the ACPBM and PPCA were analyzed by SEM, EDX, BET, and FT-IR, which showed that PEI had been successfully loaded on the surface of ACPBM. It was found that when the impregnated PEI concentration is $1 \%$, the adsorbent dosage is $3 \mathrm{~g} \cdot \mathrm{L}^{-1}$, the contact time is $180 \mathrm{~min}$, the concentration of initial $\mathrm{Cr}(\mathrm{VI})$ is $5 \mathrm{mg} \cdot \mathrm{L}^{-1}$, and the $\mathrm{pH}$ is 2 , the maximum adsorption capacity for $\mathrm{Cr}(\mathrm{VI})$ can reach $1.58 \mathrm{mg} \cdot \mathrm{g}^{-1}$. The process of PPCA adsorption of $\mathrm{Cr}(\mathrm{VI})$ conformed to the Freundlich isotherm model and the quasi-second-order kinetic model, indicating that the adsorption is multi-molecular layer adsorption with the adsorption mechanism of ion exchange and electrostatic attraction. In adsorption thermodynamics, $\Delta \mathrm{H}_{0}>0, \Delta \mathrm{G}_{0}<0$, and $\Delta \mathrm{S}_{0}>0$, indicating that the 
process of adsorbing $\mathrm{Cr}(\mathrm{VI})$ by the $1 \% \mathrm{PPCA}$ is an endothermic entropy increase reaction that can proceed spontaneously. This study shows that a green, recyclable, and degradable high-performance PPCA adsorbent has been prepared through traditional papermaking processes and physical impregnation methods, which has a significant removal effect on low-concentration hexavalent chromium ions and can be industrialized.

Keywords Activated carbon paper-based material; Polyethyleneimine; Adsorption; low-concentration hexavalent chromium

\section{Introduction}

It is a global issue that the drinking water's security and no polluted drinking water is becoming a scarce resource (Liu et al.2021). In recent years, fast development continually along with industrialization and urbanization, industries the electronics industry, electroplating, petrochemical industry, leather tanning, and papermaking have brought benefits while also leaving pollution, especially chromium slag pollution (Ellis et al.2002; Kobya et al.2004). These chromium slags are not equipped with anti-seepage measures. Under the scouring of rainwater, they may seep into the ground, causing certain pollution to underground drinking water and threatening human health (Fu et al.2011). Chromium presences in two forms in water systems; one is $\mathrm{Cr}(\mathrm{III})$, the other is $\mathrm{Cr}(\mathrm{VI})$ (Guan et al.2019). $\mathrm{Cr}(\mathrm{III})$ is one of the essential elements in animals (Huang et al. 2019). However, $\mathrm{Cr}(\mathrm{VI})$ is a very toxic substance, it is easily absorbed by the skin, causing cancer in human cells (Zhang et al. 2010; Lai et al. 2008). It has been considered as one of the heavy metals to be removed preferentially. Therefore, it is urgent to develop an efficient and environmentally friendly way to remove $\mathrm{Cr}$ (VI) in water (Chowdhury et al. 2016; Azimi et al. 2017).

The current methods for removing $\mathrm{Cr}(\mathrm{VI})$ in water commonly include membrane separation (Kozlowski et al. 2002), photocatalysis (Xu et al. 2019), ion exchange (Rengaraj et al. 2001), electrodialysis (Jin et al. 2016), and adsorption (Zhang et al. 2019; Sun et al. 2010) etc. The adsorption method is often used to remove $\mathrm{Cr}(\mathrm{VI})$ in water due to its flexible utilization, and easy availability. (Pang et al. 2011; Jin et al. 2017). There are a variety of adsorbents, including barks (Sudaryanto et al. 2021), chitosan (Zhang et al. 2021), nano-crystalline-cellulose (Tasrin et al. 2020), mesoporous silica (Li et al. 2021), activated carbon (Mojdeh et al. 2010), and synthetic hydrogel (Zhao et al. 2021), etc. 
Activated carbon is widely used because relatively large specific surface area and rich pore distribution (Sun et al. 2013). Activated carbon can be divided into fibrous, granular, and powder form according to the appearance and shape. Among them, activated carbon powder has the best adsorption effect (Choi et al. 2008). When activated carbon powder is put into sewage alone, some may be dissolved in the water, causing secondary pollution and increasing energy consumption for treatment. In the household water purifier, the activated carbon powder is compressed into a cake shape, which reduces the loss of the activated carbon powder. However, the operation method of this method is relatively cumbersome, and it cannot be recovered. For further improvement, activated carbon powder can be combined with other substrates to construct activated carbon-based bulk materials. This method not only solves the problem of the loss of activated carbon powder but also the method is simple in process, the adsorbent is easy to recover.

Polyethyleneimine (PEI) is a high molecular polymer with abundant amino and imino groups, which can chelate with heavy metals (Ma et al. 2014). However, PEI directly applied as an adsorbent shows the disadvantages of easy loss. PEI needs to be fixed to another matrix to remove heavy metals. Common fixation methods include physical impregnation and chemical grafting or cross-linking (Xing et al. 2021). Mojdeh Owlad (Mojdeh et al. 2010) immersed activated carbon in PEI water solution to prepare an absorbent to remove $\mathrm{Cr}(\mathrm{VI})$. When the initial concentration of hexavalent chromium ions is $10 \mathrm{mg} \cdot \mathrm{L}^{-1}$, its adsorption capacities reach $22 \mathrm{mg} \cdot \mathrm{g}^{-1}$ with a maximum removal rate of $80 \%$, and the remaining hexavalent chromium concentration is $2 \mathrm{mg} \cdot \mathrm{L}^{-1}$. To further improve the loading rate of PEI, Pan (Pan et al. 2018) used glutaraldehyde as cross-linking agent to combine PEI with activated carbon by crosslinking method and explored the material's capacity to adsorb $\mathrm{Cr}(\mathrm{VI})$ in wastewater. We can find that when the initial concentration of $\mathrm{Cr}(\mathrm{VI})$ is $350 \mathrm{mg} \cdot \mathrm{L}^{-1}$, the removal rate is up to $98 \%$, and the adsorption capacity is up to $500 \mathrm{mg} \cdot \mathrm{g}^{-1}$. The concentration of remaining hexavalent chromium ion is 7 $\mathrm{mg} \cdot \mathrm{L}^{-1}$. Even though they have a certain adsorption effect on $\mathrm{Cr}(\mathrm{VI})$, the remaining hexavalent chromium does not meet the industry's highest emission standard $\left(\leqslant 0.5 \mathrm{mg} \cdot \mathrm{L}^{-1}\right)$ and the highest chromium content standard in drinking water $\left(<0.05 \mathrm{mg} \cdot \mathrm{L}^{-1}\right)$. Moreover, the cross-linking agent is commonly toxic and harms the human body.

In this paper, we use the traditional papermaking method to prepare an activated carbon paper-based matrix material made of activated carbon powder, softwood pulp, and polyester fiber, which improved the utilization value of activated carbon powder. In addition, a non-toxic adhesive of polyvinyl alcohol 
(PVA) was used to realize the facile fixing of PEI to the matrix by a straightforward way of dip-coating. The influence of $\mathrm{pH}$, PEI concentration, Contact time, temperature, adsorbent dosage, and $\mathrm{Cr}(\mathrm{VI})$ initial concentration on the $\mathrm{Cr}(\mathrm{VI})$ adsorption capacity in water were extensively explored, and the adsorption mechanism of adsorbent for hexavalent chromium was further discussed.

\section{Experimental section}

\subsection{Materials}

Softwood pulp was purchased from Dalian Yangrun Trading Co., Ltd. (Dalian, Liaoning). The polyester fiber was provided by Weifang Long Fiber Co., Ltd. (Weifang, Shandong). Cationic polyacrylamide (CPAM) was purchased from Puyi Environmental Protection Technology Co., Ltd (Shanghai, China). Activated carbon (20 mesh), purchased from Luzhi, Pingdingshan City Original Activated Carbon Co., Ltd. (Pingdingshan, Henan). Potassium dichromate, diphenylcarbazide, polyethyleneimine, acetone, sulfuric acid, and polyvinyl alcohol used in the experiment were all analytically pure and they were Provided by Shanghai Aladdin Biochemical Technology Co., Ltd. (Shanghai, China).

\subsection{Preparation of activated carbon paper-based materials}

First, weigh a certain amount of softwood pulp, polyester fiber, and activated carbon powder(The oven-dry basis ratio is $42: 10: 48$, The basis weight is $240 \mathrm{~g} \cdot \mathrm{m}^{-2}$ ) into a decomposing tank, decompress $2000 \mathrm{r}$ to prepare an even suspension. Secondly, add diluted CPAM and PAE (The additive amount of CPAM is $0.08 \%$, PAE is $0.8 \%$ ) to dissolve $2000 \mathrm{r}$. The decomposed mixed raw materials are converted into wet paper using a paper sheet former. The wet paper is placed in a blast drying oven (temperature controlled at $115^{\circ} \mathrm{C}$ ) for 20 min to make activated carbon paper-based materials (ACPBM).

\subsection{Preparation of PEI/PVA solution}

First, $20 \mathrm{~g}$ of PVA was added into a beaker with $250 \mathrm{~mL}$ of deionized water and mechanically stirred for $1 \mathrm{~h}$ at $60{ }^{\circ} \mathrm{C}$, followed by raising the temperature to $90{ }^{\circ} \mathrm{C}$ and continue stirring for another $2 \mathrm{~h}$ to prepare 8 wt.\% PVA solution. Secondly, use deionized water to dilute $50 \%$ PEI solution to $0.5 \%, 1 \%$, $2 \%$, and $5 \%$ for use. Finally, the desired amount of PVA and PEI solutions (a mass ratio of 4:1) were mixed and magnetically stirred in a water bath for $30 \mathrm{~min}$ at $30{ }^{\circ} \mathrm{C}$ to prepare PEI/PVA solutions with different concentrations.

\subsection{Preparation of PEI/PVA composite activated carbon paper-based material}

A desired amount of ACPBM was immersed in PEI/PVA mixture solutions with different 
concentrations for $2 \mathrm{~min}$, taken out, followed by drying in a $70{ }^{\circ} \mathrm{C}$ blast drying oven for $1 \mathrm{~h}$. The PEI/activated carbon paper-based composite materials (PPCA) were prepared. PPCA impregnated with different concentrations of PEI are named 0.5\%PPCA, 1\%PPCA, 2\%PPCA, and 5\%PPCA.

\subsection{Characterization of adsorbent}

119 The surface morphology and size of ACPBM, 1\%PPCA before and after the adsorption of Cr(VI)were characterized using scanning electron microscopy (SEM). Energy-dispersive X-ray spectroscopy (EDX) elemental maps were obtained during SEM testing. The surface functional groups of PPCA at different impregnation concentrations were analyzed using an FT-IR spectrometer (FTS-3000) at 600-4000 $\mathrm{cm}^{-1}$. The pore size distribution and specific surface area of the sample are evaluated using the $\mathrm{N}_{2}$ adsorption and desorption isotherm obtained by BET at $77 \mathrm{k}$.

\subsection{Adsorption experiments}

Weigh $0.1414 \mathrm{~g}$ of potassium dichromate baked to a constant weight at $105-110^{\circ} \mathrm{C}$ and dissolve it with $500 \mathrm{~mL}$ of pure water to prepare a $\mathrm{Cr}(\mathrm{VI})$ stock solution with $100 \mathrm{mg} \cdot \mathrm{L}^{-1}$, which was diluted to a series of concentrations as needed. A Cr(VI) solution with a certain concentration was put into $50 \mathrm{~mL}$ colorimetric tubes with stoppers and diluted to the mark by adding deionized water. Subsequently, 2.5 $\mathrm{mL}$ of 10 wt.\% sulfuric acid solution and $2.5 \mathrm{~mL}$ of $2.5 \mathrm{~g} \cdot \mathrm{L}^{-1}$ diphenylcarbazide solution were added immediately. After standing for $10 \mathrm{~min}$, put it in a $1 \mathrm{~cm}$ colorimetric tube and measure the absorbance with a dark box three-purpose ultraviolet spectrophotometer at a wavelength of $540 \mathrm{~nm}$. The standard curve of $\mathrm{Cr}(\mathrm{VI})$ is shown in Figure. 1.

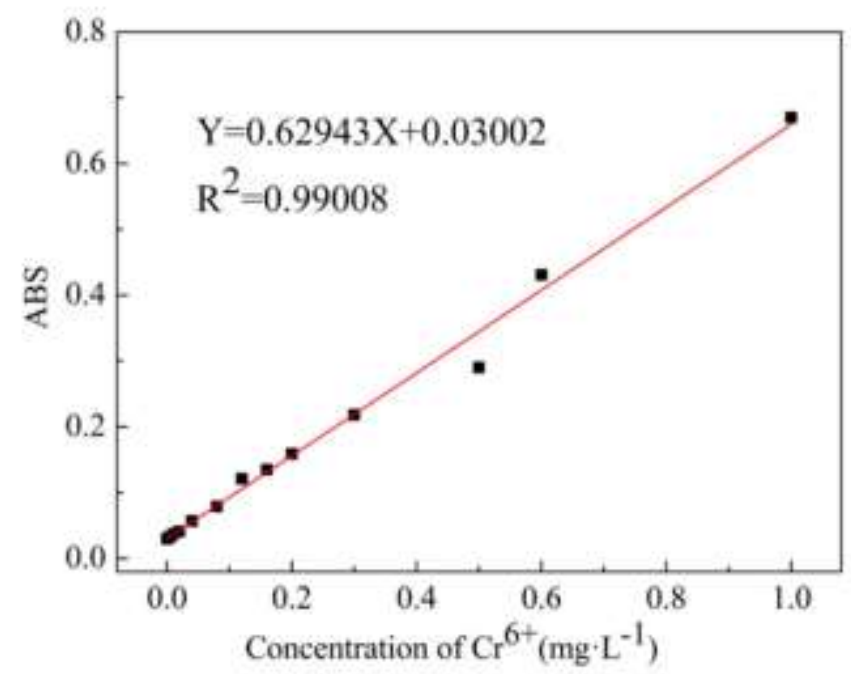

Fig.1 Standard curve diagram of $\mathrm{Cr}^{6+}$ 
$\mathrm{mL}$ conical flask, then add a certain quality of ACPBM and PPCA, which was placed in a shaker with a pre-set temperature, and magnetically stirred at $170 \mathrm{rpm}$ for various time duration. Subsequently, after taking it out, filter the solution with a $0.45 \mu \mathrm{m}$ filter membrane, The absorbance was measured by the above method, and the concentration of $\mathrm{Cr}(\mathrm{VI})$ is obtained according to Figure 1.

The experiment separately explored the influence of concentrations of PEI/PVA solution $(0.5,1,2,3$, and $5 \%), \mathrm{pH}(2,4,6,8$, and 10$)$, and absorbent dosage $\left(1,3\right.$, and $\left.5 \mathrm{~g} \cdot \mathrm{L}^{-1}\right)$ on the $\mathrm{Cr}(\mathrm{VI})$ adsorption performance. To study the adsorption mechanism of $1 \%$ PPCA, we conducted an experimental investigation on its adsorption kinetics. Briefly, $0.3 \mathrm{~g}$ of $1 \% \mathrm{PPCA}$ was added in a solution of $100 \mathrm{~mL}$, $\mathrm{pH}$ of 2, hexavalent chromium concentration of $5 \mathrm{mg} \cdot \mathrm{L}^{-1}$, and a temperature of $303 \mathrm{~K}$ for different absorption time $(0.5,1,1.5,2,2.5,3,3.5,4,4.5,5,5.5$, and $6 \mathrm{~h})$. In addition, in the adsorption thermodynamic experiment, other conditions remain unchanged, and the adsorption was carried out at 293, 303, and $313 \mathrm{~K}$ for $3 \mathrm{~h}$. The adsorption isotherm experiment was carried out by changing the initial concentrations of $\mathrm{Cr}(\mathrm{VI})$ solution $\left(1,5\right.$, and $\left.15 \mathrm{mg} \cdot \mathrm{L}^{-1}\right)$ and keeping the temperature at $303 \mathrm{~K}$ to adsorb for $3 \mathrm{~h}$. Based on the obtained adsorption data, thermodynamic parameters $\left(\Delta \mathrm{G}_{0}, \Delta \mathrm{H}_{0}\right.$, and $\left.\Delta \mathrm{S}_{0}\right)$ were determined.

\section{Results and discussion}

\subsection{Characterization}

The surface morphology of ACPBM and 1\% PPCA were observed by SEM. It can be seen from Figure 2a that softwood pulp fiber is the main component of ACPBM. Because the surface of polyester fiber is relatively smooth, it has a poor binding force with plant fibers. Therefore, the polyester fiber is arranged alternately with softwood pulp fiber in a network form. Activated carbon powder adheres to the surface of the fiber. From figure $3 \mathrm{~b}$, it can be seen that there is a glue-like substance between the fiber and the fiber, which makes the pore size of the material smaller, indicating that the PEI has been successfully loaded on ACPAM. Figure 2c is the SEM image of 1\% PPCA after $\mathrm{Cr}(\mathrm{VI})$ adsorption. From Figure 2c, it can be seen that softwood pulp fibers swell due to water immersion, while polyester fibers are not affected. We also performed EDX analysis on the adsorbed material, we found that besides $\mathrm{C}, \mathrm{N}$, and $\mathrm{O}$ elements, there is also the presence of $\mathrm{Cr}$ element in the material, which also fully shows that the 1\%PPCA has an adsorption effect on $\mathrm{Cr}(\mathrm{VI})$.

From Figure 3a, we can get that the nitrogen adsorption capacity of the adsorbent increases with the increase of relative pressure. According to the classification of isotherms, it belongs to category VI 
isotherms. In the lower $\mathrm{P} / \mathrm{P}_{0}$ zone, the capillary condensation of nitrogen occurs and agglomerates in the micropores on the inner surface area, which increases the adsorption capacity, the isotherm rises rapidly, and the curve is convex. With the increase of $\mathrm{P} / \mathrm{P}_{0}$, when all pores have capillary aggregation, adsorption only occurs on the outer surface, much smaller than the inner surface, and the adsorption amount rises slowly. When the relative pressure is close to 1, nitrogen is adsorbed on the macropores, and the curve rises. In the range of $\mathrm{P} / \mathrm{P}_{0}$ of $0.43-1.0$, the isotherm shows an obvious hysteresis loop. According to the classification of IUPAC, it belongs to the category VI mesoporous hysteresis ring, which shows that ACPBM is mainly composed of mesopores and micropores, and the pore structure is irregular. As shown in Figure 3a, it was found that as the concentration of impregnated PEI/PVA becomes larger, the adsorption capacity becomes smaller, which implies that PEI/PVA may adhere to the pores of activated carbon, resulting in a decrease in the specific surface area (Table 1) of the material and a decrease in the adsorption sites provided for nitrogen. The adsorption amount becomes smaller. It can be seen from the figure that the pores of ACPBM are mainly distributed between $2-16 \mathrm{~nm}$, and the pores of $1 \% \mathrm{PPCA}$ and $2 \% \mathrm{PPCA}$ are mainly distributed between $2-10 \mathrm{~nm}$. This is mainly because the addition of PEI blocks the macropores.

The surface chemical structure of adsorbent impregnated with different concentrations of PEI/PVA solution was analyzed by infrared spectroscopy, as presented in Figure 4. The samples all showed typical characteristic absorption peaks of cellulose, such as $-\mathrm{OH}$ stretching vibration $\left(3270 \mathrm{~cm}^{-1}\right)$, $\mathrm{CH}_{2}$-stretching vibration $\left(2880 \mathrm{~cm}^{-1}\right), \mathrm{C}-\mathrm{H}$ bending vibration $\left(1558 \mathrm{~cm}^{-1}\right)$, and $\mathrm{C}-\mathrm{O}-\mathrm{C}$ stretching vibration $\left(1057 \mathrm{~cm}^{-1}\right)\left(\right.$ Shao et al.2021). The characteristic absorption peaks at $1705 \mathrm{~cm}^{-1}$ are the $\mathrm{C}=\mathrm{O}$ stretching vibrations in the polyester fiber, respectively (Ricardo et al ,2015). From figure 4, we can also get that as the concentration of the coated PEI increases, there is an obvious small peak near 1650 $\mathrm{cm}^{-1}$, which is the result of the N-H bending vibration of PEI. In addition, PEI should have N-H stretching vibration peaks and C-N stretching vibration peaks at $3270 \mathrm{~cm}^{-1}$ and $1045 \mathrm{~cm}^{-1}$ (Hong et al, 2021). However, we found that ACPBM, $0.5 \% \mathrm{PPCA}, 1 \% \mathrm{PPCA}$, and $2 \% \mathrm{PPCA}$ all have characteristic peaks at these two wavelengths. The $\mathrm{N}-\mathrm{H}$ and the $\mathrm{C}-\mathrm{N}$ stretching vibration peak in the PEI are covered by the $\mathrm{O}-\mathrm{H}$ and the C-O-C stretching vibration peak in the cellulose, respectively. The above analysis shows that PEI has been successfully loaded onto the ACPBM. 

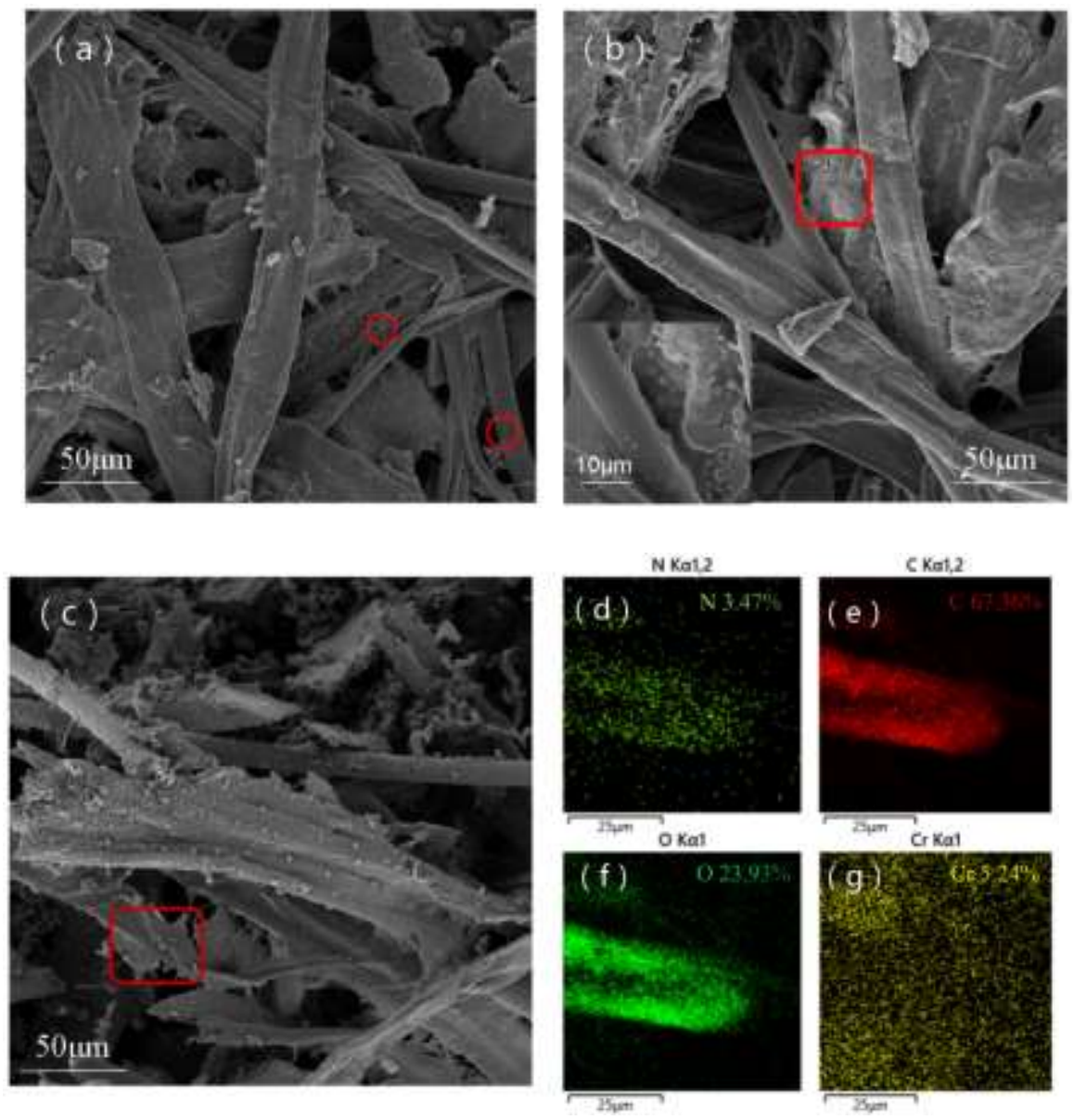

Fig.2 SEM image of ACPBM (a) and 1\% PPCA (b); SEM image of 1\% PPCA after adsorption of $\mathrm{Cr}$

198 (VI) (c); EDX elemental mapping images of the 1\% PPCA after adsorption of Cr (VI) (d, e, f, and g)
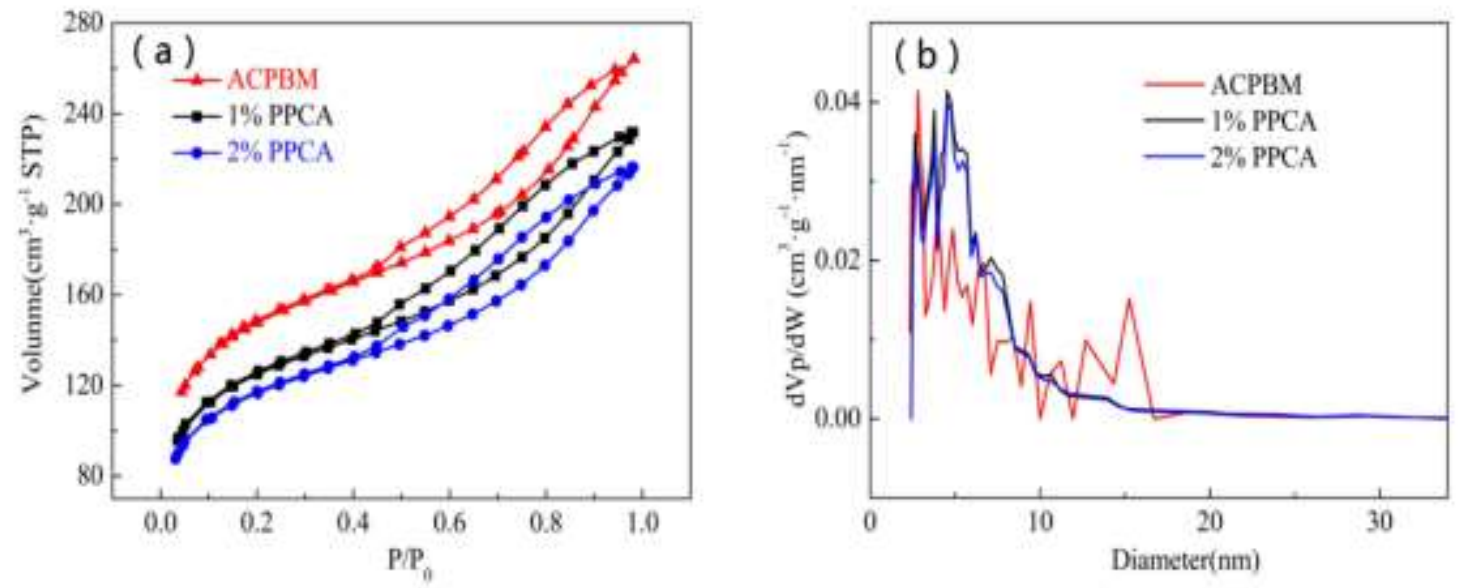

200 Fig.3 $\mathrm{N}_{2}$ adsorption-desorption isotherms (a) and pore size distribution (b) of ACPBM, 1\% PPCA and

$201 \quad 2 \%$ PPCA

Table 1 Pore structure characteristics of ACPBM,1\%PPCA 和 2\%PPCA 


\begin{tabular}{lll}
\hline ACPBM & 521.86 & 0.4088 \\
$1 \%$ PPCA & 454.25 & 0.3322 \\
$2 \%$ PPCA & 424.61 & 0.3103 \\
\hline
\end{tabular}
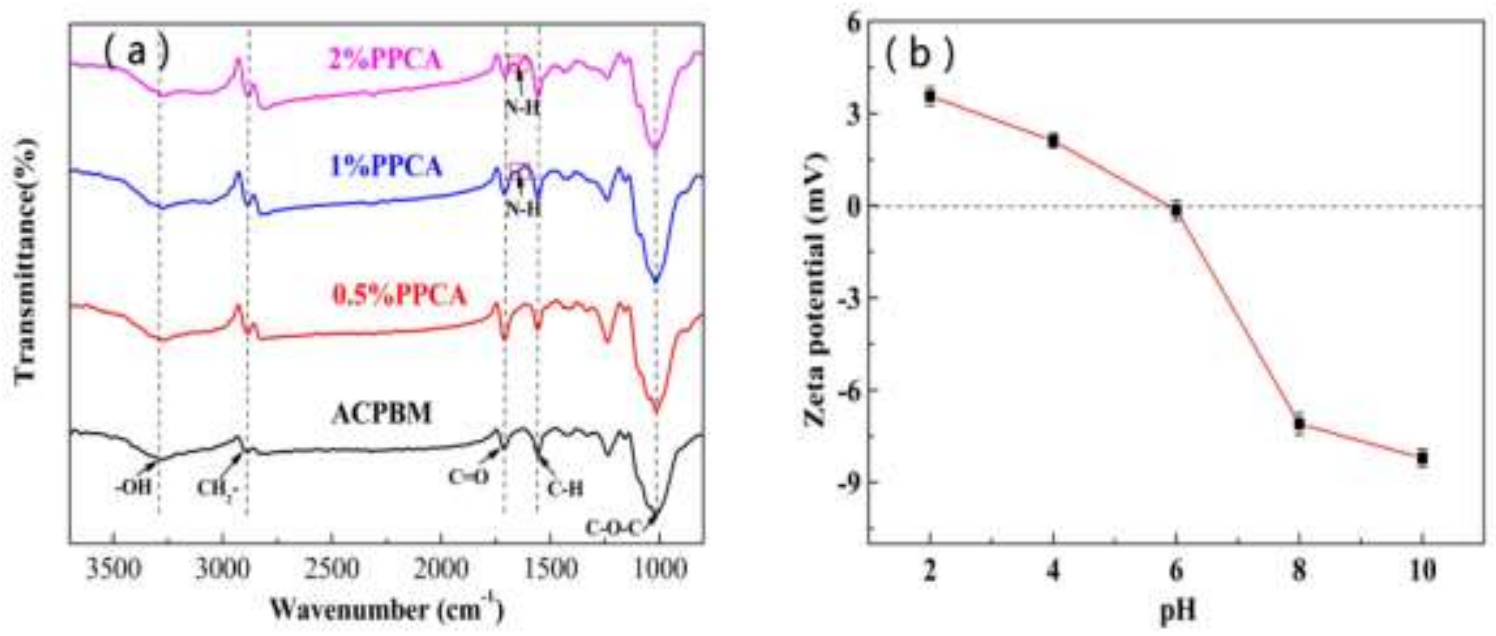

205 Fig.4 FTIR spectra of ACPBM,0.5\%PPCA,1\%PPCA and 2\%PPCA (a); zeta-potential of 1\%PPCA with 206 various $\mathrm{pH}$ in deionized water (b)

3.2 Effects of PEI\&PVA solution concentration
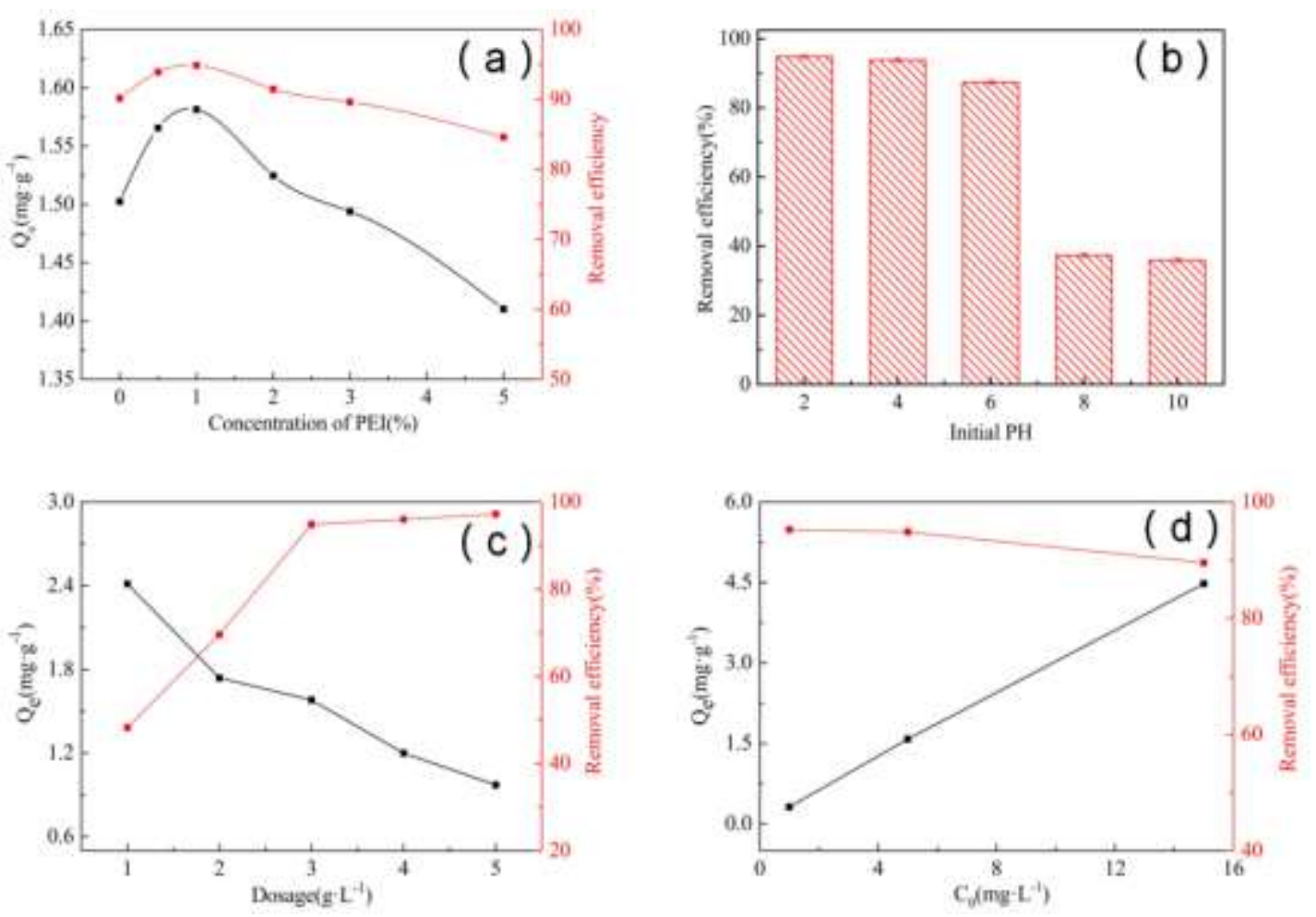
Fig.5 The effect of PEI concentration (a), pH (b), dosage (c) and $\mathrm{Cr}(\mathrm{VI})$ initial concentration(d) on the Cr (VI) adsorption capacity and removal rate

211 Figure 5a shows the effect of PPCA impregnated with different concentrations of PEI\&PVA on the removal rate and adsorption amount of $\mathrm{Cr}(\mathrm{VI})$. From figure 5a, we can get that the removal rate is $90.15 \%$, and the adsorption amount of $\mathrm{Cr}(\mathrm{VI})$ by ACPBM is $1.50 \mathrm{mg} \cdot \mathrm{g}^{-1}$. The adsorption capacity and removal rate of the adsorbent for $\mathrm{Cr}(\mathrm{VI})$ increase with the impregnated PEI/PVA concentration. When the impregnated PEI/PVA concentration is $1 \%$, the adsorption amount and removal rate of adsorbent to $\mathrm{Cr}(\mathrm{VI})$ reaches the maximum value of $1.58 \mathrm{mg} \cdot \mathrm{g}^{-1}$ and $94.88 \%$, respectively. This is mainly because not only the activated carbon has an adsorption effect on $\mathrm{Cr}(\mathrm{VI})$, but also the amino groups in PEI can remove $\mathrm{Cr}(\mathrm{VI})$ through chelation. As the concentration of impregnation increases, the amino groups in the adsorbent increase so that the ability to remove $\mathrm{Cr}(\mathrm{VI})$ becomes stronger. The concentration of impregnation continues to increase, and the adsorption effect of adsorbent on $\mathrm{Cr}(\mathrm{VI})$ decreases. This is mainly because a large amount of PEI adheres to the surface of the activated carbon, resulting in a decrease in the specific surface area (Table 1) of the activated carbon and a decrease in the adsorption sites provided for $\mathrm{Cr}(\mathrm{VI})$, giving rise to the decreasing of the adsorption performance of $\mathrm{Cr}(\mathrm{VI})$.

\subsection{Effects of initial PH}

$\mathrm{Cr}(\mathrm{VI})$ mainly exists in three forms: $\mathrm{Cr}_{2} \mathrm{O}_{7}{ }^{2-}, \mathrm{CrO}_{4}{ }^{2-}$, and $\mathrm{HCrO}_{4}^{-}$in solution, and the mutual conversion between them is affected by $\mathrm{pH}$ (Pan et al. 2018). Under acidic conditions, $\mathrm{Cr}(\mathrm{VI})$ in the solution mainly exists in the form of $\mathrm{Cr}_{2} \mathrm{O}_{7}{ }^{2-}$ and $\mathrm{HCrO}_{4}^{-}$. With the increase of $\mathrm{pH}$, the content of hydrogen ions conditions or neutral conditions, Hexavalent chromium ions mainly exists in $\mathrm{CrO}_{4}{ }^{2-}$ (Sun et al. 2013; main factor that affects the density of PEI cationic charge. The stronger the protonation ability of the amino groups on the PEI surface, the greater the cationic charge density on the surface. It has a strong adsorption effect on the anions existing in the solution.

From figure $5 b$, we can find that when $\mathrm{pH}=2$, the removal rate reaches the maximum value of $95 \%$. As the $\mathrm{pH}$ value increases, the removal rate gradually decreases. This is mainly because, in the acidic solution of $\mathrm{pH}=2$, there is more hydrogen ion content in the solution, making the amino groups in PEI easier to protonate. Thereby, $\mathrm{HCrO}_{4}^{-}$and $\mathrm{Cr}_{2} \mathrm{O}_{7}{ }^{2-}$ existing in the form of anions in the solution can be 
better electrostatically absorbed. With the $\mathrm{pH}$ increases, the content of hydrogen ions in the solution decreases, which weakens the protonation ability of the amino groups in PEI, and reduces the electrostatic adsorption performance of the 1\%PPCA to hexavalent chromium ions. From the results of Zeta potential (Fig. 4b), we can find that the high adsorption efficiency under low $\mathrm{pH}$ conditions is due to a strong electrostatic attraction between the positively charged nitrogen $\left(\mathrm{N}^{+}\right)$and the $\mathrm{Cr}(\mathrm{VI})$ existing in the form of anions. When $\mathrm{pH}=2,1 \% \mathrm{PPCA}$ has the best adsorption performance for $\mathrm{Cr}(\mathrm{VI})$, so a $\mathrm{pH} 2$ is selected for the following experiments.

\subsection{Effects of dosage}

From figure $5 \mathrm{c}$, we know that when the dosage of $1 \%$ PPCA increased from $1 \mathrm{~g} \cdot \mathrm{L}^{-1}$ to $3 \mathrm{~g} \cdot \mathrm{L}^{-1}$, the removal rate of $\mathrm{Cr}(\mathrm{VI})$ increased significantly, from $44.44 \%$ to $94.45 \%$. The main reason is that in the initial stage of the adsorption, 1\%PPCA is small, and the adsorption sites provided are few. With the increase in the amount of $1 \%$ PPCA, the adsorption sites of chromium ions increase, which significantly improves the adsorption effect. Continue to increase the amount of input, and the $\mathrm{Cr}(\mathrm{VI})$ removal rate will remain balanced. This is mainly because the adsorption of hexavalent chromium ions in water by $1 \%$ PPCA has reached adsorption equilibrium. Even if the dosage is increased, the removal rate of $\mathrm{Cr}(\mathrm{VI})$ will not be significantly improved.

\subsection{Effects of time and temperature}

From figure $6 \mathrm{a}$, we can get that as the adsorption contact time increases, the adsorption capacity also increases. When the contact time is $180 \mathrm{~min}$, the adsorption capacity reaches the maximum value of $1.58 \mathrm{mg} \cdot \mathrm{g}^{-1}$. This is mainly because the $1 \% \mathrm{PPCA}$ did not reach the adsorption equilibrium in the initial adsorption stage. As the contact time increases, the adsorbent can continue to adsorb $\mathrm{Cr}(\mathrm{VI})$. When the contact time further increases from $180 \mathrm{~min}$ to $360 \mathrm{~min}$, the adsorption capacity is unchanged, which indicates that the adsorption has reached the adsorption equilibrium.

From figure 6a, we also can get that the amount of adsorption increases with the increase of temperature, which shows that temperature rise is conducive to the adsorption of $\mathrm{Cr}(\mathrm{VI})$ in water. When the temperature increased from $20{ }^{\circ} \mathrm{C}$ to $30{ }^{\circ} \mathrm{C}$, the adsorption capacity increases significantly from $1.37 \mathrm{mg} \cdot \mathrm{g}^{-1}$ to $1.53 \mathrm{mg} \cdot \mathrm{g}^{-1}$. When further increases the temperature from $30{ }^{\circ} \mathrm{C}$ to $40{ }^{\circ} \mathrm{C}$, the adsorption capacity increases slowly. Thus, the temperature of $30{ }^{\circ} \mathrm{C}$ is the optimal adsorption condition.

\subsection{Adsorption kinetics}



adsorption kinetic models, namely the quasi-first-order, the quasi-second-order adsorption kinetic equation, and the intra-particle diffusion model (Xiao et al. 2017). Fitting the adsorption data with these three equations can explore the adsorption mechanism of the adsorbent.

273 The quasi-first-order adsorption kinetic equation is the proportional relationship between the reaction adsorption rate and the concentration of reactants, and its linear expression (Indra et al. 2005) is:

276 Where $\mathrm{Q}_{\mathrm{e}}$ is the equilibrium adsorption capacity $\left(\mathrm{mg} \cdot \mathrm{g}^{-1}\right), \mathrm{Q}_{\mathrm{t}}$ is the adsorption capacity at time $\mathrm{t}$

$277\left(\mathrm{mg} \cdot \mathrm{g}^{-1}\right)$, and $\mathrm{k}_{1}$ is the reaction rate constant of the quasi-first order adsorption kinetic equation.

278 The quasi-second-order kinetic equation assumes that the adsorbent and the adsorbate undergo a 279 chemical reaction, and the adsorption rate is affected by the chemical adsorption mechanism. This process involves the gains and losses of electrons or the sharing of electrons. Its linear expression

281 (Indra et al. 2005) is:

$$
\frac{t}{Q_{t}}=\frac{t}{Q_{e}}+\frac{1}{k_{2} Q_{e}}
$$

283 Where $\mathrm{k}_{2}$ is the adsorption rate constant of the quasi-second-order kinetic equation, $\mathrm{h}=\mathrm{k}_{2} \mathrm{Q}_{\mathrm{e}}$ is the initial 284 adsorption rate constant $\left(\mathrm{mg} \cdot \mathrm{g}^{-1} \cdot \mathrm{h}^{-1}\right)$

285 The intra-particle diffusion model is mainly used to describe the process of adsorbent diffusion to the surface of the adsorbent through macropores or micropores. Its linear expression (Indra et al. 2005) is:

$$
287 Q_{t}=k_{3} t^{\frac{1}{2}}+Q_{e}
$$

288 Where $\mathrm{k}_{3}$ is the diffusion rate constant within the particle $\left(\mathrm{mg} \cdot \mathrm{g}^{-1} \cdot \mathrm{h}^{-0.5}\right)$, the larger the value, the easier 289 the adsorbate diffuses inside the adsorbent.

290 Table 2 Adsorption kinetics and intra-particle diffusion model parameters for the adsorption of $\mathrm{Cr}(\mathrm{VI})$ 291 by $1 \%$ PPCA

Quasi-first-order adsorption kinetic equation Quasi-second-order adsorption kinetic equation

\begin{tabular}{lllllll}
\hline $\mathrm{q}_{\text {e.exp }}$ & $\mathrm{Q}\left(\mathrm{mg} \cdot \mathrm{g}^{-1}\right)$ & $\mathrm{K}_{1}\left(\mathrm{~h}^{-1}\right)$ & $\mathrm{R}^{2}$ & $\mathrm{Q}\left(\mathrm{mg} \cdot \mathrm{g}^{-1}\right)$ & $\mathrm{K}_{2}\left(\mathrm{~g} \cdot \mathrm{mg}^{-1} \cdot \mathrm{h}^{-1}\right)$ & $\mathrm{R}^{2}$ \\
$\left(\mathrm{mg} \cdot \mathrm{g}^{-1}\right)$ & & & & & & \\
1.58512 & 1.14285 & 0.65112 & 0.94274 & 1.74182 & 1.24651 & 0.99485
\end{tabular}


$\mathrm{Q}_{1}\left(\mathrm{mg} \cdot \mathrm{g}^{-1}\right) \quad \mathrm{K}_{3}\left(\mathrm{mg} \cdot \mathrm{g}^{-1} \cdot \mathrm{h}^{-0.5}\right) \quad \mathrm{R}^{2} \quad \mathrm{Q}_{1}\left(\mathrm{mg} \cdot \mathrm{g}^{-1}\right) \quad \mathrm{K}_{3}\left(\mathrm{mg} \cdot \mathrm{g}^{-1} \cdot \mathrm{h}^{-0.5}\right) \quad \mathrm{R}^{2}$

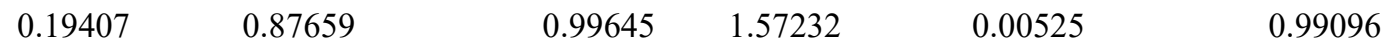

292 According to the data in figure $6(\mathrm{~b}, \mathrm{c})$ and table 2 , we can get the $\mathrm{R}^{2}$ of the quasi-first-order adsorption

293 kinetic equation to be 0.94274 , and the adsorption capacity is $\mathrm{Q}_{\mathrm{e}}=1.14285 \mathrm{mg} \cdot \mathrm{g}^{-1}$, the

294 quasi-second-order adsorption kinetic equation is $\mathrm{R}^{2}=0.99485, \quad \mathrm{Q}_{\mathrm{e}}=1.74182 \mathrm{mg} \cdot \mathrm{g}^{-1}$. The

295 quasi-second-stage adsorption kinetic equation not only has a high degree of fit, but also its $Q_{\mathrm{e}}$ is closer

296 to qe. exp.

297 From figure 6 (d) and table 2, we can find the process of 1\%PPCA adsorption of Cr(VI) can be 298 divided into two stages. The $\mathrm{R}^{2}>0.99$ of the two stages indicates that $\mathrm{Q}_{\mathrm{t}}$ has a linear relationship with

$299 \mathrm{t}^{0.5}$, and there is intra-particle diffusion in this process. The $\mathrm{K}_{3}$ of the first stage is 0.87659 , and the $\mathrm{K}_{3}$ 300 of the second stage is 0.00525 . It shows that the adsorbent in the first stage is prone to internal 301 diffusion in the adsorbate. This is mainly because there is a large concentration difference between the $3021 \%$ PPAC surface and the $\mathrm{Cr}(\mathrm{VI})$ at the beginning of the reaction, and the mass transfer driving force is 303 large. Particles are mainly diffused by macropores, so particle diffusion is easy with. As the reaction 304 progresses, the adsorption sites on the surface of 1\%PPCA are gradually occupied by chromium ions, 305 which reduces the adsorption rate. At this time, the particles diffuse mainly through the micropores inside the adsorbate. 

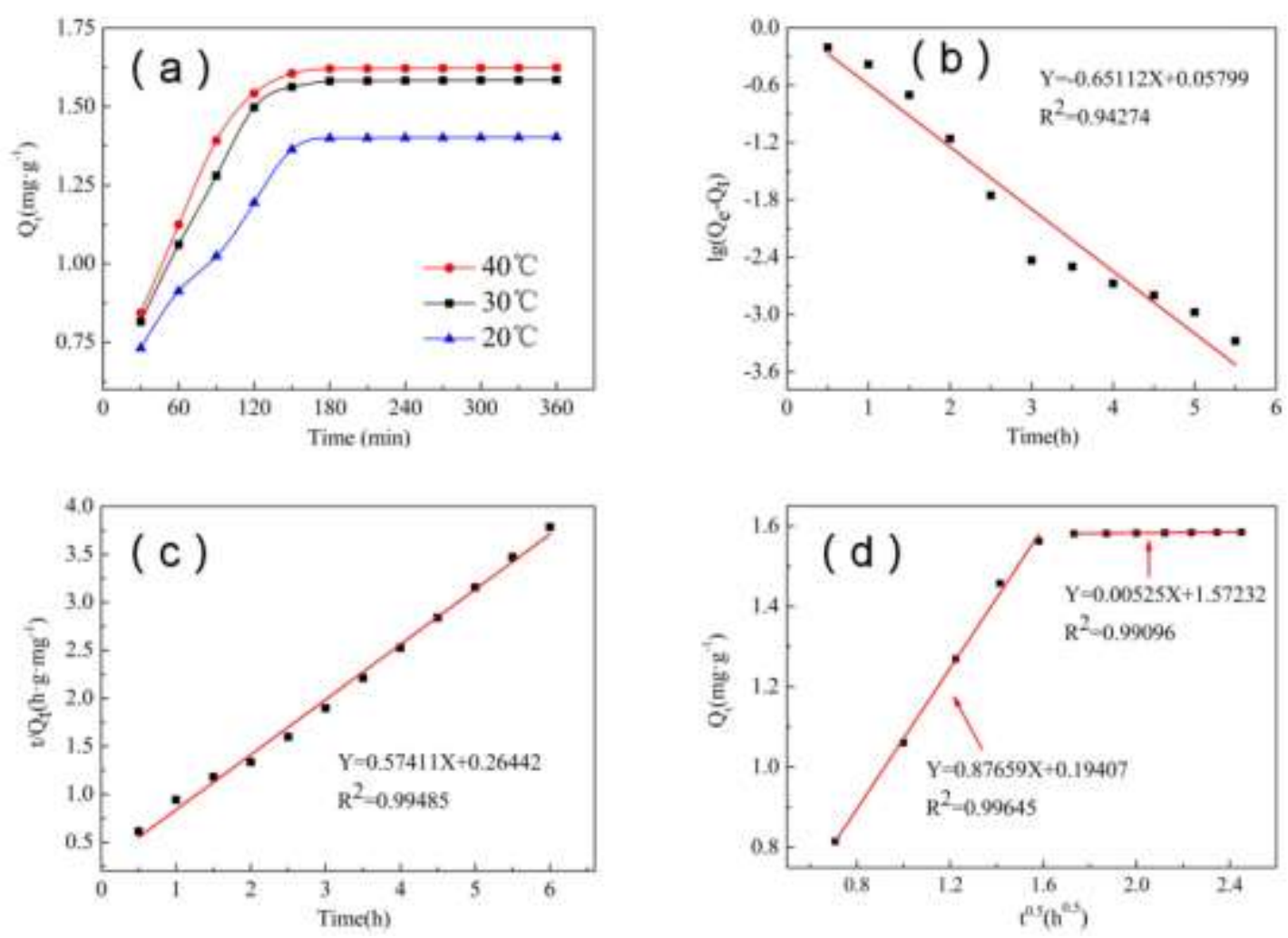

Fig.6 The effect of time and $\mathrm{pH}$ on $\mathrm{Cr}(\mathrm{VI})$ adsorption(a); The adsorption kinetics of $\mathrm{Cr}(\mathrm{VI})$ adsorption by $1 \%$ PPCA (b: linear plot of pseudo-first-order; $\mathbf{c}$ : pseudo-second-order; $\mathbf{d}$ : Intraparticle diffusion model)

\subsection{Adsorption isotherm}

The adsorption isotherm expresses the relationship between adsorption capacity and solution concentration when adsorption reaches equilibrium at a certain temperature. It can describe the mechanism of action between adsorbate and adsorbent, which has a great effect in exploring the surface characteristics of adsorbate and adsorbent (Guo et al. 2017a; Guo et al. 2017b).

The Langmuir isotherm is used to show that the adsorption reaction is a monolayer surface adsorption. Many uniform adsorption active sites are distributed on the adsorbent, and one molecule can only be adsorbed to one active site. (Charpentier et al. 2016). When the surface adsorption active sites are all occupied, the adsorption capacity reaches the saturation value. The equation (Indra et al. 2005) is: 
324 Where $\mathrm{C}_{\mathrm{e}}$ is the equilibrium concentration $\left(\mathrm{mg} \cdot \mathrm{L}^{-1}\right) ; \mathrm{Q}_{0}$ is the maximum adsorption capacity for single-molecule adsorption $\left(\mathrm{mg} \cdot \mathrm{g}^{-1}\right)$; $\mathrm{b}$ is the Langmuir constant, which indicating the binding force between the adsorbent and the adsorbate.

The Freundlich isotherm indicates that the adsorption reaction belongs to multi-molecular layer adsorption (Lin et al. 2017a; Lin et al. 2017b). The active adsorption sites are unevenly arranged on the adsorbent. The equation (Indra et al. 2005) is:

$\lg Q_{e}=\lg K_{F}+\frac{\lg C_{e}}{n}$

Where $\mathrm{K}_{\mathrm{F}}$ is the equilibrium adsorption constant, which reflects the strength of the adsorption capacity; $1 / \mathrm{n}$ is the composition factor, which indicates the strength of the adsorption capacity increases with the concentration, and reflects the difficulty of adsorption.

From figure $7(a, b)$ and table 3, we can know the parameters of the Freundlich adsorption isotherm are $\mathrm{R}^{2}=0.99074, \mathrm{R}^{2}>0.99$. It shows that the Freundlich adsorption isotherm better reflects the adsorption behavior of $1 \% \mathrm{PPCA}$ to hexavalent chromium ion, which also concludes that the adsorption of $1 \%$ PPCA on hexavalent chromium ion is multi-molecular layer adsorption. It can be seen from the table that $\mathrm{n}=1.45161, \mathrm{n}>1$, indicating that the adsorption reaction is easy to proceed with. The parameters of Langmuir adsorption isotherm are $\mathrm{R}^{2}=0.96827$, which also reflects the adsorption behavior. From table 3, We can also find that the maximum adsorption capacity of $1 \%$ PPCA for hexavalent chromium ion is $6.62032 \mathrm{mg} \cdot \mathrm{g}^{-1}$.

Table 3 Adsorption isotherm parameters for the adsorption of $\mathrm{Cr}(\mathrm{VI})$ by $1 \% \mathrm{PPCA}$

\begin{tabular}{llll}
\hline & Freundlich & \multicolumn{1}{c}{ Langmuir } \\
\hline equation & $\mathrm{Y}=0.68889 \mathrm{X}+0.56174$ & & $\mathrm{Y}=0.15105 \mathrm{X}+0.10708$ \\
$\mathrm{R}^{2}$ & 0.99074 & $\mathrm{R}^{2}$ & 0.96827 \\
$K_{\mathrm{F}}\left(\mathrm{mg} \cdot \mathrm{g}^{-1}\right)$ & 3.64535 & $1 / Q_{0}\left(\mathrm{~g} \cdot \mathrm{mg}^{-1}\right)$ & 0.15105 \\
$1 / \mathrm{n}$ & 0.68889 & $Q_{0}\left(\mathrm{mg} \cdot \mathrm{g}^{-1}\right)$ & 6.62032 \\
$\mathrm{n}$ & 1.45161 & $\mathrm{~b}$ & 1.41063 \\
\hline
\end{tabular}


344 To explain the effect of temperature on the adsorption of chromium ions, it is very important to 345 calculate the thermodynamic constants of adsorption. The thermodynamic isotherm is mainly used to evaluate the change of energy and entropy of the adsorbent during the adsorption process. The equation between the Gibbs free energy change $\left(\Delta \mathrm{G}_{0}\right)$ and the distribution coefficient $\mathrm{K}_{\mathrm{D}}$ (Indra et al. 2005) is: $\Delta G_{0}=-R T \ln K_{D}$

349 The equations of enthalpy change $\left(\Delta \mathrm{H}_{0}\right)$, entropy change $\left(\Delta \mathrm{S}_{0}\right)$ and $\Delta \mathrm{G}_{0}$ (Indra et al. 2005) are as follows :

$\Delta G_{0}=\Delta H_{0}-T \Delta S_{0}$

352 Combining the two formulas can get the Vanter Hoff equation (Indra et al. 2005):

353

$\ln K_{D}=-\frac{\Delta G_{0}}{R T}=\frac{\Delta S_{0}}{R}-\frac{\Delta H_{0}}{R T}$

Where $\mathrm{R}$ is the gas constant $0.008314 \mathrm{~kJ} \cdot \mathrm{mol}^{-1} \cdot \mathrm{K}^{-1}$; $\mathrm{T}$ is the absolute temperature $\mathrm{K}$.

Figure $7 \mathrm{c}$ and table 4 , we can find that the adsorption process of $1 \% \mathrm{CCPA}$ on $\mathrm{Cr}(\mathrm{VI})$ is $\Delta \mathrm{H}_{0}=57.67$ $\mathrm{kJ} \cdot \mathrm{mol}^{-1}, \Delta \mathrm{H}_{0}>0$, indicating that this reaction is endothermic. The adsorption performance gradually increases with the increase of temperature. This is also consistent with the aforementioned increase in process of $1 \% \mathrm{CCPA}$ on $\mathrm{Cr}(\mathrm{VI})$ is $\Delta \mathrm{S}_{0}=262.4 \mathrm{~J} \cdot \mathrm{mol}^{-1} \cdot \mathrm{K}^{-1}$. We can conclude that during the adsorption freedom of the liquid-solid surface increase. From table 4 , we can also find that $\Delta \mathrm{G}_{0}<0$, indicating that this reaction can proceed spontaneously. And as the temperature increases, $\Delta \mathrm{G}_{0}$ gradually becomes 

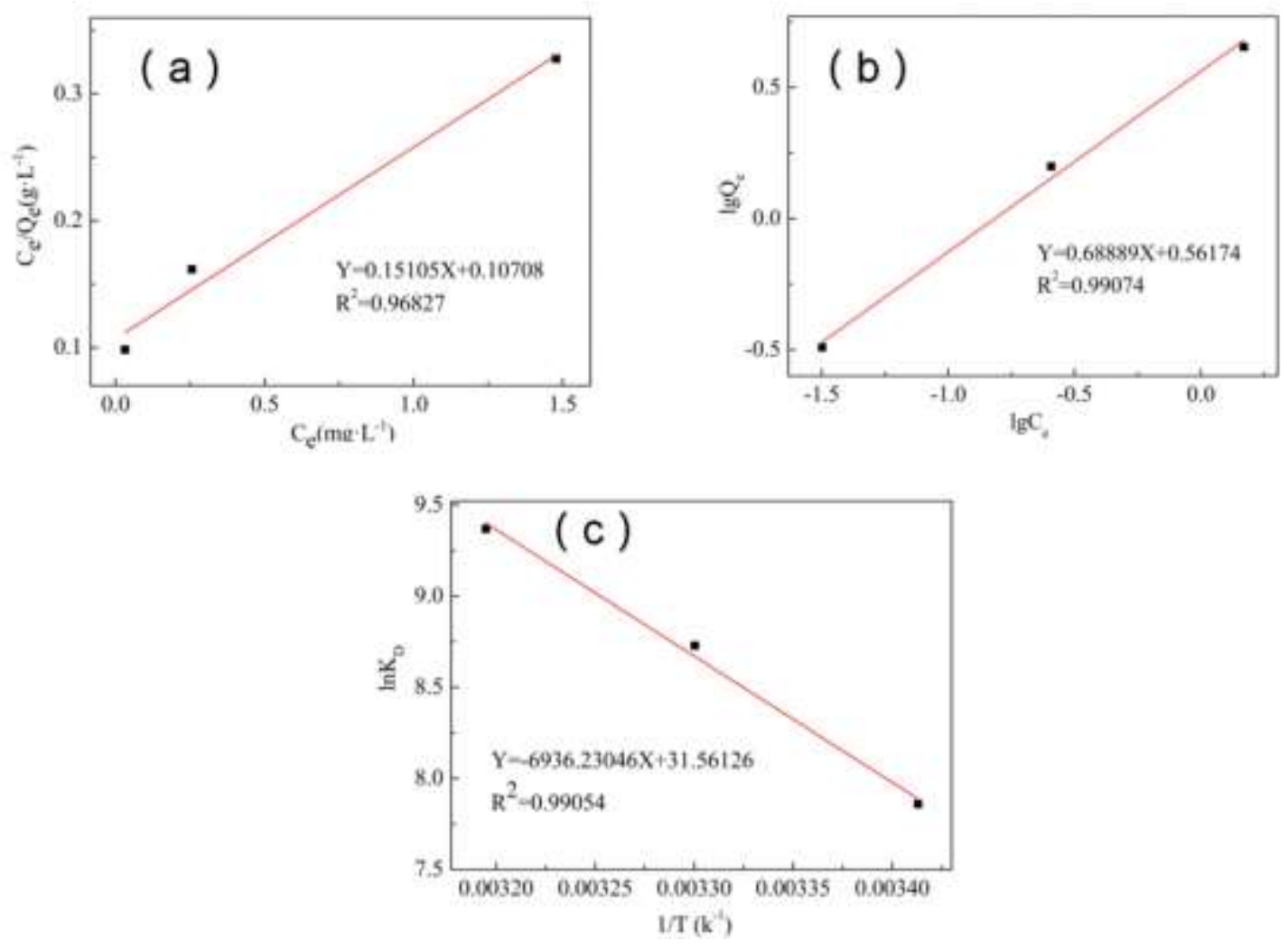

366 Fig.7 The adsorption isotherms of the Langmuir (a) and Freundlich (b); the adsorption isotherm equation(c)

Table 4 Adsorption thermodynamics parameters for the adsorption of $\mathrm{Cr}(\mathrm{VI})$ by $1 \% \mathrm{PPCA}$

\begin{tabular}{llllll}
\hline & $\Delta H_{0}\left(\mathrm{~kJ} \cdot \mathrm{mol}^{-1}\right)$ & $\Delta S_{0}\left(\mathrm{~J} \cdot \mathrm{mol}^{-1} \cdot \mathrm{K}^{-1}\right)$ & $\mathrm{T}(\mathrm{K})$ & $\Delta G_{0}\left(\mathrm{~kJ} \cdot \mathrm{mol}^{-1}\right)$ & $\mathrm{R}^{2}$ \\
\hline & & 293 & -19.213 & \\
$\operatorname{Cr}(\mathrm{VI}) \quad 57.67$ & 262.4 & 303 & -21.807 & 0.99054 \\
& & & 313 & -24.461 & \\
\hline & & &
\end{tabular}

370 In this work, we prepared a PEI/PVA composite activated carbon paper-based adsorbent that can

371 efficiently remove low-concentration $\mathrm{Cr}(\mathrm{VI})$. The adsorption effect of the $1 \% \mathrm{PPCA}$ was greatly

372 affected by the $\mathrm{pH}$, and the optimal $\mathrm{pH}$ was 2 . At this time, the adsorption capacity can reach 1.58

$373 \mathrm{mg} \cdot \mathrm{g}^{-1}$. We performed a fitting analysis of adsorption kinetics, isotherms, and thermodynamic 374 equations on the adsorption data. The results show that the adsorption kinetics conforms to the 375 quasi-second-stage adsorption kinetic equation, indicating that a chemical reaction between the 376 paper-based material and $\mathrm{Cr}(\mathrm{VI})$ and the rate of adsorption is controlled by the mechanism of chemical 377 adsorption. The Freundlich adsorption isotherm better reflects the adsorption behavior of $1 \%$ PPCA on 
$\mathrm{Cr}(\mathrm{VI})$, indicating that the adsorption of $\mathrm{Cr}(\mathrm{VI})$ to the adsorbent is multi-molecular layer adsorption. In adsorption thermodynamics, $\Delta \mathrm{H}_{0}=57.67 \mathrm{~kJ} \cdot \mathrm{mol}^{-1}, \Delta \mathrm{H}_{0}>0, \Delta \mathrm{G}_{0}<0$, indicating that the process of adsorbing $\mathrm{Cr}(\mathrm{VI})$ by the adsorbent is an endothermic reaction that can proceed spontaneously. And $\Delta \mathrm{S}_{0}=262.4 \mathrm{~J} \cdot \mathrm{mol}^{-1} \cdot \mathrm{K}^{-1}$; this reaction increases entropy, the complexity, and stability of adsorption and the degree of freedom of liquid-solid surface increase during the adsorption process. In general, this study prepared a green adsorbent through simple papermaking and impregnation physical methods, which has a certain removal performance for drinking water containing low concentrations of $\mathrm{Cr}(\mathrm{VI})$. The adsorbent is prepared by traditional papermaking and physical impregnation methods and can be produced in large quantities.

\section{References}

Azimi A, Azari A, Rezakazemi M, Ansarpour M(2017)Removal of heavy metals from industrial wastewaters: a review. ChemBioEng Rev 4:37-59.https://doi.org/10.1002/cben.201600010

Charpentier TVJ, Neville A, Lanigan JL, Barker RJ, Richardson T (2016)Preparation of magnetic carboxymethylchitosan nanoparticles for adsorption of heavy metal ions. ACS Omega 1:7783.https://doi.org/10.1021/acsomega.6b00035

Choi K J, Kim S G, Kim S H(2008) Removal of tetracycline and sulfonamide classes of the antibiotic compound by powdered activated carbon. Environmental Technology 29:333342.https://doi.org/10.1080/09593330802102223

Chowdhury S, Mazumder MJ, Al-Attas O, Husain T (2016)Heavy metals in drinking water: Occurrences, implications, and future needs in developing countries. Total Environ 569-570:476488.https://doi.org/10.1016/j.scitotenv.2016.06.166

Ellis AS, Johnson TM, Bullen T D (2002)Chromium Isotopes and the Fate of Hexavalent Chromium in the Environment. Science 295:2060-2062.https://doi.org/10.1126/science.1068368

Fu F, Wang Q(2011)Removal of Heavy Metal Ions from Wastewaters: A Review. J Environ Manage 92:407-418. https://doi.org/10.1016/j.jenvman.2010.11.011

Guan X, Yang H, Sun Y, Qiao J (2019) Enhanced immobilization of chromium(VI) in soil using sulfidated zero-valent iron. Chemosphere 228:370376.https://doi.org/10.1016/j.chemosphere.2019.04.132

Guo DM, An QD, Xiao ZY, Zhai SR, Shi Z (2017a) Polyethylenimine-functionalized cellulose aerogel beads for efficient dynamic removal of chromium(vi) from aqueous solution. RCS Adv 7:5403954052.https://doi.org/10.1039/c7ra09940a

Guo XZ, Ding L, Kanamori K, Nakanishi K, Yang H (2017b) Functionalization of hierarchically porous silica monoliths with polyethyleneimine (PEI) for $\mathrm{CO}_{2}$ adsorption. Micropor Mesopor Mat 254:51-57.https://doi.org/10.1016/j.micromeso.2017.02.076

Hong HJ, Ban G, Kim HS, Jeong HS, Park MS (2021) Fabrication of cylindrical 3D cellulose nanofibril(CNF) aerogel for continuous removal of copper(Cu2+) from wastewater. Chemosphere 278:130288-130288. https://doi.org/10.1016/J.CHEMOSPHERE.2021.130288 

removal from aqueous solution using biochar modified with $\mathrm{Mg} / \mathrm{Al}$-layered double hydroxide intercalated with ethylene-diaminetetraacetic acid. Bioresource Technol 276:127-132. https://doi.org/10.1016/j.biortech.2018.12.114

Indra DM, Vimal CS, Nitin KA, Indra MM (2005) Removal of congo red from aqueous solution by bagasse fly ash and activated carbon: Kinetic study and equilibrium isotherm analyses. Chemosphere 61:492-501. https://doi.org/10.1016/j.chemosphere.2005.03.065

Jin W, Du H, Zheng S, Zhang Y (2016) Electrochemical processes for the environmental remediation of toxic $\mathrm{Cr}(\mathrm{VI}):$ a review. Electrochim Acta 191:1044-1055. https://doi.org/10.1016/j.electacta.2016.01.130

Jin X, Xiang Z, Liu Q, Chen Y, Lu F (2017) Polyethyleneiminebacterial cellulose biosorbent for effective removal of copper and lead ions from aqueous solution. Bioresource Technol 244:844849. https://doi.org/10.1016/j.biortech.2017.08.072

Kobya M (2004) Removal of Cr(VI) from Aqueous Solutions by Adsorption onto Hazelnut Shell Activated Carbon: Kinetic and Equilibrium Studies. Bioresour Technol. 91:317321.https://doi.org/10.1016/j.biortech.2003.07.001

Kozlowski CA, Walkowiak W (2002) Removal of Chromium(VI) from Aqueous Solutions by Polymer Inclusion Membranes. Water Res 36:4870-4876 https://doi.org/10.1016/S0043-1354(02)00216-6

Lai KCK, Lo IC (2008) Removal of Chromium (VI) by Acid-Washed Zero-Valent Iron Under Various Groundwater Geochemistry Conditions.Environ Sci Technol 42,12381244.https://doi.org/10.1021/es071572n

Li SL, Li SQ, Wen N, Wei D, Zhang YF (2021) Highly effective removal of lead and cadmium ions from wastewater by bifunctional magnetic mesoporous silica.Separation and Purification Technology 265:118341-118352.https://doi.org/10.1016/J.SEPPUR.2021.118341

Lin F, You Y, Yang X, Jiang X, Lu B (2017a) Microwave-assisted facile synthesis of TEMPO-oxidized cellulose beads with high adsorption capacity for organic dyes. Cellulose 24:50255040.https://doi.org/10.1007/s10570-017-1473-9

Lin Y, Hong Y, Song Q, Zhang Z, Gao J, Tao T (2017b) Highly efficient removal of copper ions from water using poly(-acrylic acid)-grafted chitosan adsorbent. Colloid Polym Sci 295:627635.https://doi.org/10.1007/s00396-017-4042-8

Liu P, Cai WQ, Chen JW, Yang ZC, Zhou JP, Cai ZJ, Fan JJ (2021) One-pot hydrothermal preparation of manganese-doped carbon microspheres for effective deep removal of hexavalent chromium from wastewater.Journal of Colloid and Interface Science 599:427435.https://doi.org/10.1016/j.jcis.2021.04.098

Ma Y, Liu WJ, Zhang N, Li YS, Jiang H, Sheng GP (2014) Polyethylenimine modified biochar adsorbent for hexavalent chromium removal from the aqueous solution. Bioresour Technol 169:403-408.https://doi.org/10.1016/j.biortech.2014.07.014

Mojdeh O, Mohamed KA, Wan MAWD (2010) Hexavalent chromium adsorption on impregnated palm shell activated carbon with polyethyleneimine. Bioresour Technol 101:50985103.https://doi.org/10.1016/j.biortech.2010.01.135

Pan RR, Zou JX, Li Y, Jin XJ (2018) Hyperbranched Polyethylenimine Modified Waste Fiberboard Activated Carbon for Enhanced Adsorption of Hexavalent Chromium.Journal of Wood Chemistry and Technology 3813:1-12.https://doi.org/10.1080/02773813.2017.1388820 

Magnetic Porous Powder for Highly Effective Adsorption of Heavy Metal Ions. Desalination 28:278-284. https://doi.org/10.1016/j.desal.2011.08.001

Rengaraj S, Yeon KH, Moon SH (2001) Removal of Chromium from Water and Wastewater by Ion Exchange Resins. J Hazard Mater 87:273-287.https://doi.org/10.1016/S0304-3894(01)00291-6

Ricardo M, Edwin AM (2015) Hyperbranched polyester polyol modified with polylactic acid.Journal of Applied Polymer Science 132:41589. https://doi.org/10.1002/app.41589

Sudaryanto Y, Anggorowati AA, Sianto ME (2021) Study of Pb (II) adsorption by Tannin Based Adsorbent from mangrove bark (Rhizophora mucronate).Journal of Physics: Conference Series 1858:012083-01289.https://doi.org/10.1088/1742-6596/1858/1/012086

Sun XF, Ma Y, Liu XW, Wang SG, Gao BY, Li XM (2010) Sorption and Detoxififi-cation of Chromium(VI) by Aerobic Granules Functionalized with Polyethylenimine. Water Res 44:25172524.https://doi.org/10.1016/j.watres.2010.01.027

Sun YY, Yue QY, Gao BY, Gao Y, Li Q, Wang Y (2013) Adsorption of Hexavalent Chromium on Arundodonax Linn Activated Carbon Amine-Crosslinked Copolymer. Chem Eng J 217:240 247.https://doi.org/10.1016/j.cej.2012.11.121

Tasrin S, Mohamed MFS, Padmanaban VC, Selvaraju N (2020) Surface modification of nanocellulose using polypyrrole for the adsorptive removal of Congo red dye and chromium in binary mixture. International Journal of Biological Macromolecules 151:322-332.https://doi.org/10.1016/j.ijbiomac.2020.02.181

Vedenyapina MD, Kurmysheva AY, Kulaishin SA, Kryazhev YG (2021) Adsorption of Heavy Metals on Activated Carbons (A Review),Solid Fuel Chemistry.55:83-104.https://doi.org/10.3103/S0361521921020099

Xiao C, Liu X, Mao S, Zhang LJ, Lu J (2017) Sub-micron-sized polyethylenimine-modified polystyrene/Fe3O4/chitosan magnetic composites for the effificient and recyclable adsorption of Cu(II) ions. Appl Surf Sci 394:378-385.https://doi.org/10.1016/j.apsusc.2016.10.116

Xing XY, Li WQ, Zhang J, Wu H, Guan Y, Gao H (2021) TEMPO-oxidized cellulose hydrogel for efficient adsorption of $\mathrm{Cu}^{2+}$ and $\mathrm{Pb}^{2+}$ modified by polyethyleneimine. Cellouse 28:7953-7968.https://doi.org/10.1007/S10570-021-04052-W

Xu Y, Wang D, Xie M, Jing L, Huang Y, Huang L, Xu H, Li H, Xie J (2019) Novel broad spectrum light responsive PPy/hexagonal-SnS 2 photocatalyst for efficient photoreduction of $\mathrm{Cr}(\mathrm{VI})$. Mater Res Bull 112:226-235. https://doi.org/10.1016/j.materresbull.2018.12.017

Zhang L, Fang M (2010) Nanomaterials in pollution trace detection and environmental improvement. Nano Today 5:128-142.https://doi.org/10.1016/j.nantod.2010.03.002

Zhang Y, Li M, Li J, Yang Y, Liu X (2019) Surface modified leaves with high effificiency for the removal of aqueous $\mathrm{Cr}(\mathrm{VI})$. Appl Surf $\quad$ Sci 484:189196.https://doi.org/10.1016/j.apsusc.2019.04.088

Zhang Y Z, Zhao M W, Cheng Q, Wang C, Li H J, Han X G, Fan Z H, Su G Y, Pan D, Li Z $\mathrm{Y}(2021)$ Research progress of adsorption and removal of heavy metals by chitosan and its derivatives:

A review.Chemosphere 279:130927-130927.https://doi.org/10.1016/J.CHEMOSPHERE.2021.130927

Zhao C H, Hu L L, Zhang C G, Wang S S, Wang X Z, Huo Z Y (2021) Preparation of biochar-interpenetrated iron-alginate hydrogel as a $\mathrm{pH}$-independent sorbent for removal of $\mathrm{Cr}(\mathrm{VI})$ and $\mathrm{Pb}(\mathrm{II})$.Environmental Pollution 287:117303-117303.https://doi.org/10.1016/J.ENVPOL.2021.117303 
505 Material preparation, data collection and analysis were performed by [Tianliang Gao], [Chuanshan

506 Zhao], [Sha Li], and [Xia Li]. The first draft of the manuscript was written by [Tianliang Gao] and all

507 authors commented on previous versions of the manuscript. All authors read and approved the final

508 manuscript.

509 Competing Interests

510 The authors have no relevant financial or non-financial interests to disclose.

511 Acknowledgments

512 This research was supported by the Shandong Science and Technology Program Project

513 (2015GGX102029). 